\title{
CHARACTERISATION OF NANOPARTICLE SIZE OF TIO2 USING NANOPARTICLE TRACKING ANALYSIS (NTA)
}

\author{
E. M. OLIVEIRA ${ }^{1}$, J. A CASTRO ${ }^{2}$, I. C. R. P. VALADÃO ${ }^{3}$ e A. S. F. ARAÚJO ${ }^{4}$ \\ ${ }^{1}$ Universidade Federal Fluminense, Pós-graduação em Engenharia Metalúrgica \\ E-mail para contato: beth.mendes.oliveira@gmail.com
}

\begin{abstract}
RESUMO - The study of nanoparticles involves a new bias research in various areas of technology, whose production and use have been offering multiple benefits to society. However, the uncontrolled emission to the environment of nanoparticles is growing exponentially over the last decade. Thus, knowledge of the influence of nanoparticles and how they can modify the ecosystem is extremely important and an area currently limited. Therefore, it is of fundamental importance to increase the knowledge of the fate and transport of nanoparticles in soil, in particular this research will study the $\mathrm{TiO} 2$ nanoparticles (TiNPs). This study will carry out tests on columns with soil collected in the landfill Volta Redonda located in the state of Rio de Janeiro, Brazil. The concentrations are analyzed $\mathrm{TiO}_{2}$, as well as the distribution of the size of its aggregates by Nanoparticle Tracking Analysis (NTA).
\end{abstract}

\section{INTRODUCTION}

Engineered nanomaterials (ENM) are applied in many commercially available consumer products such as in cosmetics, textiles, and paints. Due to the increasing production volumes, an environmental exposure to ENMs is likely as reported by Nowack et al., 2007. Whereas toxic effects of nanomaterials on different organisms have already been described (Klaine et al., 2008; Baun et al., 2008), measurements of environmental concentrations of ENMs are almost completely absent. The increase of applications of nanomaterials and consequent increased production are expected to cause exponentially and uncontrolled emissions in the environment.

Therefore, it is essential to understand the fate and transport of $\mathrm{T}_{\mathrm{i}} \mathrm{O}_{2}$ nanoparticles in the environment in order to assess possible routes of exposure to humans and the ecosystem for developing an understanding of the potential mobility of nanoparticles in general in the soil environment and their potential risks to groundwater. Recently, a few investigations have addressed the transport of nanoparticles in porous media (Guzman et al., 2006; Lecoanet et al., 2004; Lecoanet and Wiesner, 2004) and showed that nanoparticles including carbon nanomaterials, anatase and silica exhibited various transport behaviors.

The passage of anatase through a two-dimensional model of porous structure column slowly increased with time, suggesting that the mobility was increased with time as deposition sites became saturated (Guzman et al., 2006). Darcy velocities could also influence transport and deposition of nanoparticles and an increase in the flow velocity increased the effluent of anatase (Lecoanet $e t$ al., 
2004). However, most of these experiments were conducted in well-defined porous media, glass or polystyrene bead-packed columns and thus did not accurately represent the variety of mineral surface types, surface charge heterogeneities, grain size distributions and roughness of granular media encountered in real soil systems. Thus the environmental implications of such studies involving welldefined porous media were limited.

Many studies of the fate and impact in the environment is becoming important due to the gap of knowledge about transport in and between environmental compartments and their chemical behavior in the environment, specially for soil ecosystem (Klaine et al., 2008).

The objectives of this study were to investigate the degree to which $\mathrm{TiO} 2$ nanoparticles were suspended in suspensions and to investigate how far $\mathrm{TiO} 2$ nanoparticles could be transported in various homogeneous soil columns. The NanoSight LM20 and NTA 2.3 software were used for measuring the concentration and particle size over time. The effects of instrument settings were investigated in detail, and sensible choices suggested. The results from the NanoSight were then compared to those experimentally obtained.

\section{MATERIAL AND METHODS}

\subsection{Procedure Experimental}

Soil samples were used to cover the Municipal Landfill of Volta Redonda. TiO2 nanoparticles were purchased from Sigma Aldrich with an anatase phase purity of $99.7 \%$ and an average particle size of $25 \mathrm{~nm}$. Soil TiO2 suspensions were prepared by mixing TiO2 (500 mg) with soil (12.5 g) and adding milli-Q Watter $(250 \mathrm{~mL})$ in Erlenmeryer flasks. TiO2 in milli-Q Watter at the same ratio, with no added soil was used as control, while soil in milli-Q Watter at the same ratio without TiO2 was used as a blank.

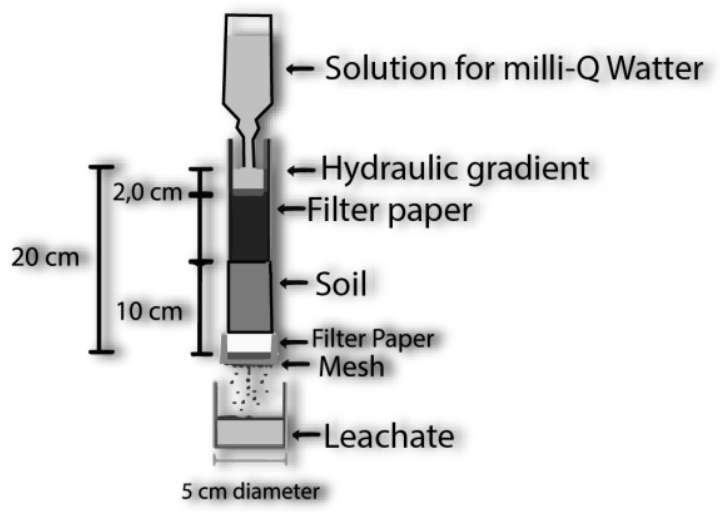

Figure 1. Schematization of Columns.

For leaching experiment, a PVC column, length $20 \mathrm{~cm}$ and inner diameter of $25 \mathrm{~mm}$ was uniformly packed with $10 \mathrm{~cm}$ of air-dried soil as shown in Figure 1. At the beginning of the experiment, the soil column was initially saturated with milli-Q Watter from the bottom of the column 
gradually upward through the entire length of the column, and then the column was leached with 100 $\mathrm{mL}$ of milli-Q Watter.

\subsection{Nanoparticle Tracking Analysis (NTA)}

After that the turbidity of outflow was measured after settling for both 0 and 10 days using Nanoparticle Tracking Analysis (NTA) as shown in Figure 2. To determine the concentration of $\mathrm{T}_{\mathrm{i}} \mathrm{O}_{2}$ nanoparticles in aqueous samples, the $\mathrm{T}_{\mathrm{i}} \mathrm{O}_{2}$ suspensionwas firstly dried in a flask by heating, the above solution was transferred quantitatively and $\mathrm{Ti}$ was determined by ICP-OES (Inductively Coupled Plasma-Optical Emission Spectroscopy). The concentration of $\mathrm{TiO} 2$ in the suspension was calculated by mass balance.

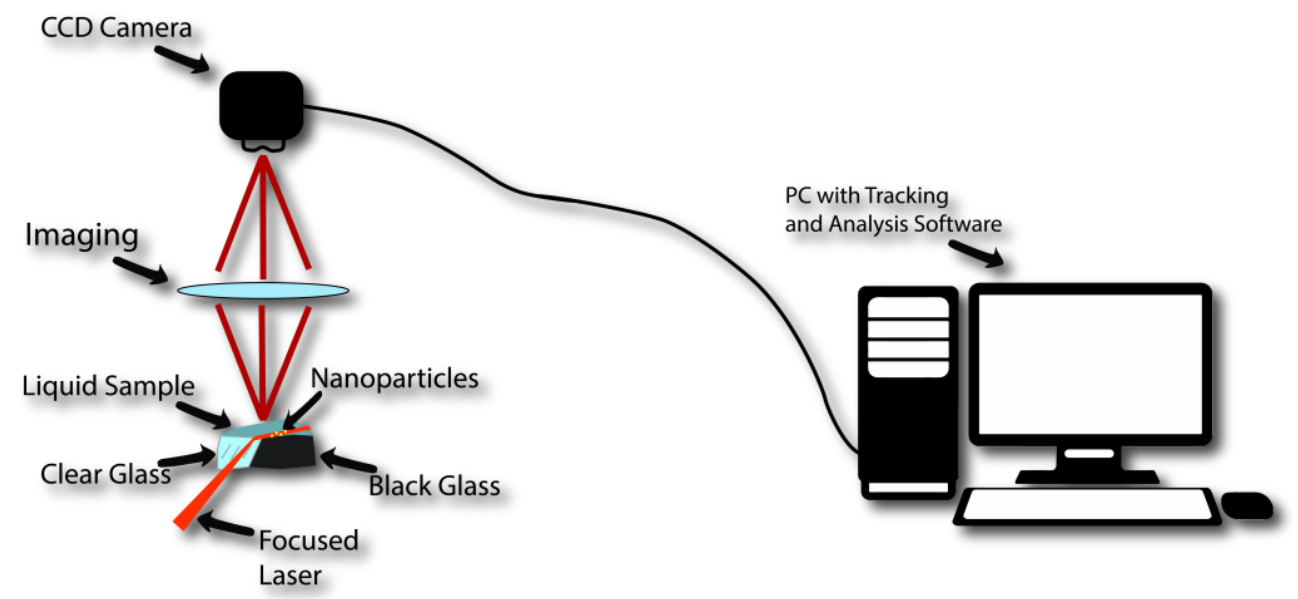

Figure 2. Schematic of the optical configuration used in NTA.

\section{RESULTS AND DISCUSSION}

During the sampling of supernatant liquid $(1 \mathrm{~mL})$, it was inevitable that the system became slightly disturbed during 10 days specifically at day 0,3,6 and 9 as shown in Figure 3-6. At time 0, aggregate size distribution of $\mathrm{T}_{\mathrm{i}} \mathrm{O} 2-\mathrm{NPs}$ suspensions was between 0.15 and $10 \mu \mathrm{m}$ with a peak at 2.7 $\mu \mathrm{m}$. These data suggest a low interaction between $\mathrm{T}_{\mathrm{i}} \mathrm{O}_{2}-\mathrm{NPs}$ and soil particles, at least in terms of aggregation or physical rearrangement. After day 3 all the suspensions showed a similar pattern, with a peak around $0.7 \mu \mathrm{m}$, suggesting that $\mathrm{TiO}_{2}-\mathrm{NPs}$ were still present as aggregates. Subsequently, the suspended $\mathrm{T}_{\mathrm{i}} \mathrm{O}_{2}$ relative concentrations decreased monotonically over the initial 2-4 days, and thereafter remained almost unchanged during the following 5-10 days. Ti concentration in the suspension (Table 1) showed an abrupt decrease, and remained constant from day 3 to 9. 

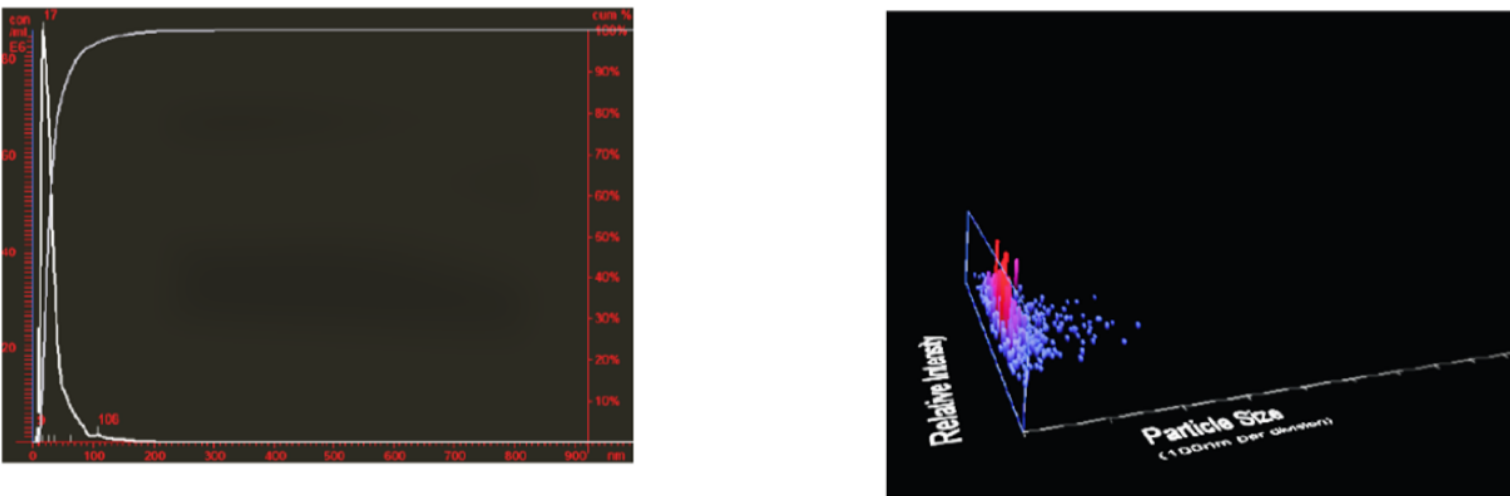

Figura 3 - Average $\mathrm{T}_{\mathrm{i}} \mathrm{O}_{2}$ particle size distribution and Relative Intensity of $\mathrm{TiO}_{2}$ in NTA (initial rate).
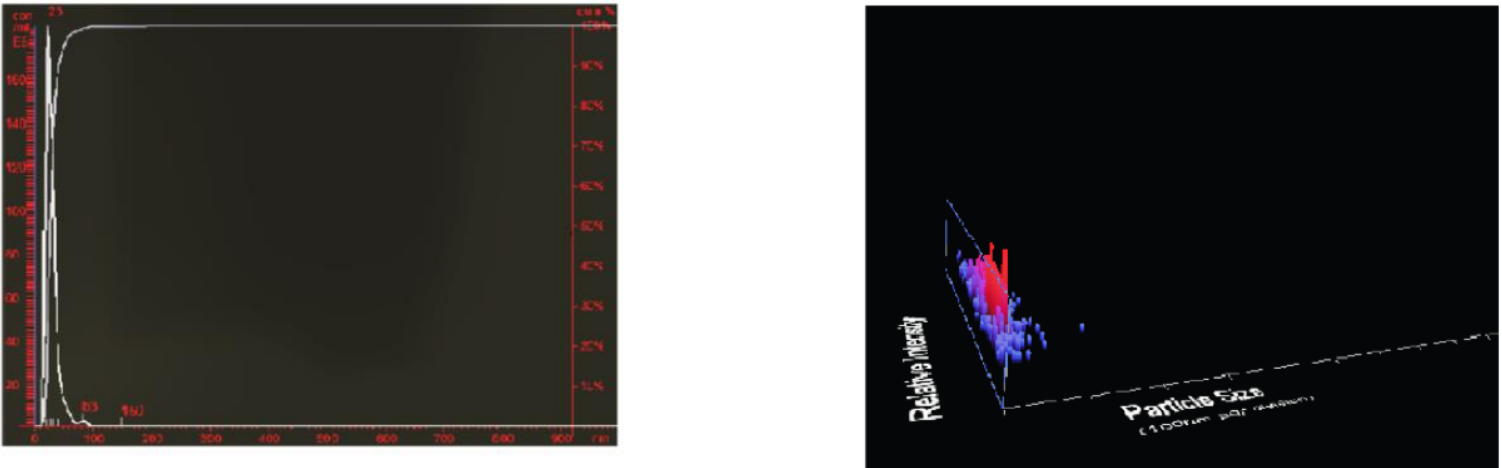

Figura 4 - Average $\mathrm{T}_{\mathrm{i}} \mathrm{O}_{2}$ particle size distribution and Relative Intensity of $\mathrm{T}_{\mathrm{iO} 2}$ in NTA (third day of decanting).
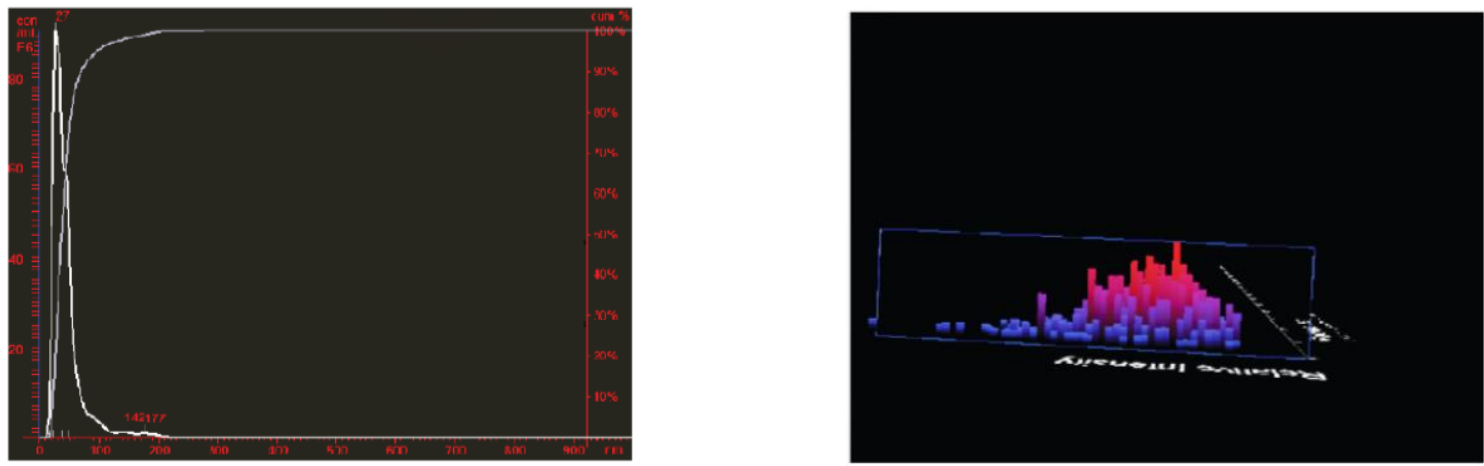

Figura 5 - Average $\mathrm{TiO} 2$ particle size distribution and Relative Intensity of $\mathrm{T}_{\mathrm{iO} 2}$ in NTA (sixth day of decanting). 

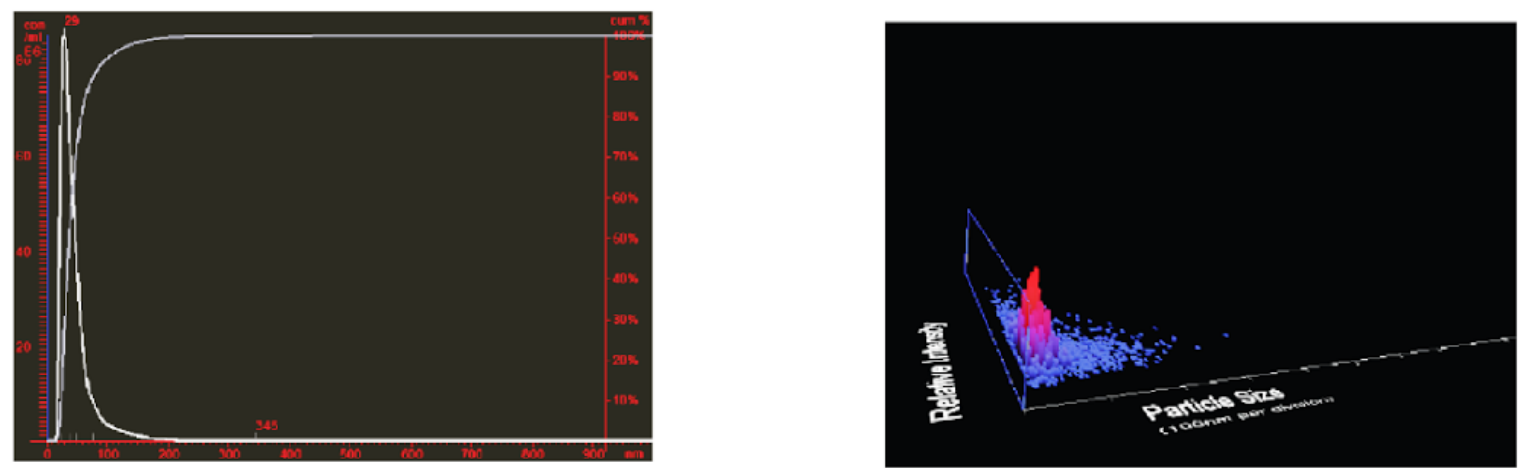

Figura 6 - Average $\mathrm{T}_{\mathrm{i}} \mathrm{O}_{2}$ particle size distribution and Relative Intensity of $\mathrm{T}_{\mathrm{iO} 2}$ in NTA (ninth day of decanting).

After the final period of solution, the suspension supernatant was collected and placed in vials for initiating drips column test. Then they had put at the bottom of the flasks column to aid in the time of percolation of $25 \mathrm{ml}$ each record. Table 1 shows the percolation time, the concentrations of $\mathrm{T}_{\mathrm{i}} \mathrm{O}_{2}$ obtained. In the three profiles observed a sharp peak growth of $\mathrm{T}_{\mathrm{i}} \mathrm{O}_{2}$ in the first 120 minutes. In subsequent minute profile depicting a sharp drop resulting in reduced $\mathrm{T}_{\mathrm{i}} \mathrm{O}_{2}$ concentration in the column outlet as a result of its retention in the soil showing that the higher the percolation time variation the lower its final leachate concentration in that turn higher concentration of nanoparticles present in the soil.

Table 1 - Percolation time, concentrations of $\mathrm{T}_{\mathrm{i}} \mathrm{O}_{2}$ obtained from experimental.

\begin{tabular}{|c|c|c|c|c|}
\hline Columns & $\begin{array}{l}\text { Percolation volume } \\
\text { accumulated (ml) }\end{array}$ & $\begin{array}{l}\mathrm{T}_{\mathrm{i}} \mathrm{O}_{2} \text { concentration } \\
(\mathrm{mg} / \mathrm{L}) \text { collected }\end{array}$ & $\begin{array}{l}\text { Percolation time } \\
(\mathrm{min})\end{array}$ & $\begin{array}{l}\text { Average time for } \\
\text { percolation (min) }\end{array}$ \\
\hline \multirow{10}{*}{ Column 1} & 25 & 0.73 & 52 & \multirow{10}{*}{373.3} \\
\hline & 50 & 3.62 & 125 & \\
\hline & 75 & 1.28 & 191 & \\
\hline & 100 & 0.83 & 237 & \\
\hline & 125 & 0.80 & 325 & \\
\hline & 150 & 0.88 & 394 & \\
\hline & 175 & 0.58 & 467 & \\
\hline & 200 & 0.46 & 549 & \\
\hline & 225 & 0.38 & 643 & \\
\hline & 250 & 0.20 & 747 & \\
\hline \multirow[b]{5}{*}{ Column 2} & 25 & 0.75 & 59 & \multirow[b]{5}{*}{372.2} \\
\hline & 50 & 2.91 & 123 & \\
\hline & 75 & 1.14 & 182 & \\
\hline & 100 & 0.90 & 248 & \\
\hline & 125 & 0.71 & 319 & \\
\hline
\end{tabular}




\begin{tabular}{|c|c|c|c|c|}
\hline & 150 & 0.71 & 389 & \\
\hline & 175 & 0.50 & 463 & \\
\hline & 200 & 0.43 & 547 & \\
\hline & 225 & 0.30 & 640 & \\
\hline & 250 & 0.29 & 752 & \\
\hline & & & & \\
\hline \multirow{10}{*}{ Column 3} & 25 & 0.62 & 58 & \multirow{10}{*}{384.4} \\
\hline & 50 & 3.44 & 121 & \\
\hline & 75 & 1.14 & 188 & \\
\hline & 100 & 0.83 & 258 & \\
\hline & 125 & 0.82 & 329 & \\
\hline & 150 & 0.78 & 402 & \\
\hline & 175 & 0.62 & 482 & \\
\hline & 200 & 0.44 & 570 & \\
\hline & 225 & 0.39 & 665 & \\
\hline & 250 & 0.30 & 771 & \\
\hline
\end{tabular}

The new peak appeared at $2.7 \mu \mathrm{m}$ in the outflow as shown in Figure 7 of the soil columns, indicating that the interactions between $\mathrm{T}_{\mathrm{i}} \mathrm{O}_{2}$ flow and the soil matrix favored the aggregation of $\mathrm{T}_{\mathrm{i}} \mathrm{O}_{2}$ nanoparticles. Where it is possible to observe that for tests where the average time was higher percolation has a smaller number of $\mathrm{T}_{\mathrm{i}} \mathrm{O}_{2}$ nanoparticles from a slower rate of percolation and consequently a greater contact time between the solid soil particles with $\mathrm{T}_{\mathrm{i}} \mathrm{O}_{2}$ nanoparticles. Hence to obtain larger amounts of retention in the soil.

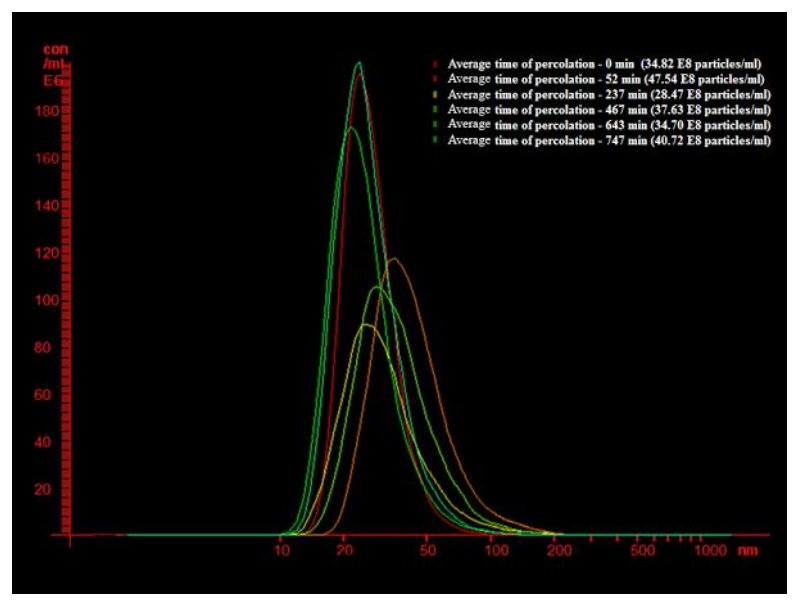

Figure 7 - Concentration of Ti (mg/l) - Average time for percolation minutes in NTA. 


\section{CONCLUSIONS}

The stabilizing propensity of nanoparticles in soil solutions is na important subject for environmental scientists to consider when assessing the risk nanomaterials pose in soil systems. The suspended $\mathrm{T}_{\mathrm{i}} \mathrm{O}_{2}$ relative concentrations decreased monotonically over the initial 2-4 days, and thereafter remained almost unchanged during the following 5-10 days. The higher stability of $\mathrm{T}_{\mathrm{i}} \mathrm{O}_{2}$ suspensions resulted in a higher mobility of $\mathrm{T}_{\mathrm{i}} \mathrm{O}_{2}$ through soil layers, resulting in reduced $\mathrm{T}_{\mathrm{i}} \mathrm{O}_{2}$ concentration in the column outlet as a result of its retention in the soil showing that the higher the percolation time variation.

\section{ACKNOWLEDGEMENTS} CNPq.

This work was supported by Conselho Nacional de Desenvolvimento Científico e Tecnológico,

\section{REFERENCES}

Baun, A.; Hartmann, N. B.; Grieger, K.; Kusk, K. O. Ecotoxicity of engineered nanoparticles to aquatic invertebrates: a brief review and recommendations for future toxicity testing. Ecotoxicology 2008, 17, 387-395.

Castro, J. A. A Multi-Dimensional Transient Mathematical Model of Blast Furnace Based on Multi-Fluid Model. Ph.D. Thesis - Institute for Advanced Materials Processing. Tohoku University. Japan. 2000.

Chen, K.L., Elimelech, M., 2007. Influence of humic acid on the aggregation kinetics of fullerence (C60) nanoparticles in monovalent and divalent electrolyte solutions. Journal of Colloid and Interface Science 309, 126-134.

Fang, J.; Shan, X.-Q.; Wen, B.; Lin, J.-m.; Owens, G. Stability of titania nanoparticles in soil suspensions and transport in saturated homogeneous soil columns. Environ. Pollut. 2009, 157 (4), 1101-1109.

Fang, J.; Shan, X.-Q.; Wen, B.; Lin, J.-m.; Owens, G. Transport of copper as affected by titania nanoparticles in soil columns Environ. Pollut. 2011, 159, 1248-1256.

Klaine, S.J., P.J.J., Alvarez, G.E., Batley, T.F., Fernandes, R.D., Handy, D.Y., Lyon, S., Mahendra, M.J., McLaughlin and J.R., Lead. 2008. Nanomaterials in the environment: Behavior, Fate, Bioavailability and Effects. Environ. Toxicol. Chem. 27:1825-1851.

Ju, B., Fan, T., Experimental study and mathematical model of nanoparticle transport in porous media. / Environmental Pollution 157 (2009) 1101-1109. 
Nagaveni, K., Sivalingam, G., Hegde, M.S., Madras, G., 2004. Photocatalytic degradation of organic compounds over combustion-synthesized nano- $\mathrm{TiO}_{2}$. Environmental Science \&Technology 38, 1600-1604.

Nowack, B., Bucheli, T.D., 2008. Occurrence, behavior and effects of nanoparticles in the environment. Environmental Pollution 150, 5-22.

Sen, T.K., Khilar, K.C., 2006. Review on subsurface colloids and colloid-associated contaminant transport in saturated porous media. Advances in Colloid and Interface Science 119, 71-96.

Shah V., Belozerova I., 2008. Influence of metal nanoparticles on soil microbial community and germination of lettuce seeds. Water, Air, \& Soil Pollution 197, 143-148.

Shas, V., M., Glene, F., Kentin, A., Tyler, G., Kent, P., Jeff, S., Mark, E., Functionalized TiO2 Nanoparticles for Use for in Situ Anion Immobilization. Environ. Sci. Technol. 2005, 39, 73067310.

Solovitch, N.; Melabille, J.; Rose, M., Borschneck, D., Wiesner, M., Yvesbottero, J.; Concurrent Aggregation and Deposition of $\mathrm{TiO}_{2}$ Nanoparticles in a Sandy Porous Media. Environ. Sci. Technol. 2010, 44, 4897-4902.

Tassi, E., R. Pini, F. Gorini, Valadão, I. C. R. P., J. A. de Castro. Chemical and Physical Soil Properties Influencing $\mathrm{TiO}_{2}$ Nanoparticles Availability in Terrestrial Ecosystems. Journal of Environmental Research And Development. 2011. Accepted.

Tadros, T.F., 2007. Colloid Stability: the Role of Surface Forces. Part I. Wiley-VCH Verlag Gmbh \& Co. kGaA, Weinheim.

Wang, Y.; Li, Y.; Fortner, J. D.; Hugnes, J. B.; Abriola, L. M.; Pennell, K. D. Transport and retention of nanoscale C60 aggregates in water-saturated porous media. Environ. Sci. Technol. 2008, 42, 3588-3594.

Wiesner, M.R., Lowry,G.V., Alvarez, P.,Dionysiou,D.,Biswas, P., 2006. Assessing the risks of manufactured nanomaterials. Environmental Science \&Technology 40, 4336-4345.

Zhang, L., Webster, T.J., 2009. Nanotechnology and nanomaterials:promises for improved tissue regeneration. Nano Today 4: 66-80.

Zhuang, J., Flury, M., Jin, Y., 2003. Colloid-facilitated Cs transport through watersaturated Hanford sediment and Ottawa sand. Environmental Science \&Technology 37, 4905-4911. 